\title{
Farinha de resíduos da indústria de filetagem de tilápias em rações para frangos de corte
}

\author{
Cinthia Eyng ${ }^{1}$, Ricardo Vianna Nunes ${ }^{2}$, Paulo Cesar Pozza ${ }^{2}$, Wagner Thiago Mozer da Silva ${ }^{3}$, \\ Franciele Clenice Navarini ${ }^{1}$, Jeffersson Rafael Henz ${ }^{3}$
}

\footnotetext{
1 Programa de Pós-graduação em Zootecnia - UNIOESTE/Marechal Cândido Rondon - PR

2 Departamento de Zootecnia - UNIOESTE/Marechal Cândido Rondon - PR.

${ }^{3}$ Graduação em Zootecnia - UNIOESTE/Marechal Cândido Rondon - PR.
}

RESUMO - Para avaliação do desempenho de frangos de corte alimentados com diferentes níveis de inclusão de farinha de resíduos da indústria de filetagem de tilápias (0, 2, 4, 6 e 8\%), foram utilizados 480 pintos de 1 dia, distribuídos em delineamento inteiramente casualizado, com cinco dietas experimentais, seis repetições e 16 aves por unidade experimental. Foram avaliados o ganho de peso, o peso final, o consumo médio de ração, a conversão alimentar e a mortalidade de 1 a 21 dias e de 1 a 42 dias de idade e, ao final do período experimental, foram mensurados os parâmetros sanguíneos (cálcio, fósforo e triglicerídeos). Para avaliação econômica, foram calculados os custos das dietas experimentais, o índice de eficiência econômica e o índice de custo. Observou-se diferença dos níveis de inclusão da farinha de tilápia sobre os parâmetros de consumo médio de ração, peso final e ganho médio de peso aos 21 dias de idade. No período total ( 1 a 42 dias), a inclusão de farinha de tilápia em níveis de até $8 \%$ na dieta não afetou o desempenho das aves. Apesar do aumento linear dos valores de triglicerídeos, esse nível de inclusão e farinha de tilápia reduz os valores de fósforo e cálcio sanguíneo e proporciona melhor desempenho econômico.

Palavras-chave: alimentos alternativos, desempenho, farinha de peixe, viabilidade econômica

\section{Meal from tilapia filleting industrial waste in rations for broiler chickens}

\begin{abstract}
For performance evaluation of broiler chickens fed different levels of meal of tilapia industrial filleting waste (0, 2, 4, 6 and 8\%), 480 chicks at 1 day of age were used in a completely randomized design with five experimental diets, six replicates and 16 birds per experimental unit. Weight gain, final weight, average feed intake, feed conversion and mortality from 1 to 21 days of age and from 1 to 42 days of age were evaluated and in the end of experimental period, blood parameters (calcium, phosphorus and triglycerides) were measured. For economical evaluation, experimental diet costs, economical efficiency index and cost index were evaluated. It was observed difference on levels of inclusion of tilapia meal on average feed intake, final weight and weight gain at 21 days of age. For the total period (from 1 to 42 days of age), the inclusion of tilapia meal at levels up to $8 \%$ of the diet did not affect performance of the birds. Despite of the linear increase in triglycerides values, this level of inclusion and tilapia meal reduce values of blood phosphorus and calcium and it provides better economical performance.
\end{abstract}

Key Words: alternative food, economic viability, fish meal, performance

\section{Introdução}

O avanço da nutrição exige cada vez mais dos nutricionistas a busca por alimentos com alta digestibilidade e que sejam economicamente viáveis. A avaliação de alimentos alternativos e seu uso na alimentação animal possibilitam a redução dos custos de produção e têm reflexos diretos na viabilidade do sistema produtivo avícola (Brum Jr. et al., 2007).

Além da preocupação com a rentabilidade do setor, segundo Geron et al. (2006) diversos subprodutos agroindustriais precisam ser estudados visando ao emprego em larga escala e à redução do seu efeito poluente. Entre eles, destacam-se os resíduos da filetagem de tilápia (cabeça, carcaça e vísceras).

O principal produto obtido do abate da tilápia é o filé, destinado ao consumo humano. Cerca de $64 \%$ da matériaprima é perdida durante o processamento, gerando grandes quantidades de resíduos com potencial para uso na alimentação animal (Ponce \& Gernat, 2002).

De acordo com Maigualema \& Gernat (2003), as farinhas de peixe comerciais são produzidas a partir de duas principais categorias. A primeira é fabricada com o resíduo obtido após o processo de filetagem destinado ao consumo 
humano e inclui espécies como tilápia e bacalhau. O segundo grupo inclui espécies como anchova, sardinha e cavala, das quais não se prioriza a retirada dos filés.

Segundo Geron et al. (2006) o resíduo de tilápia apresenta em média 68,6\% de umidade, 42,9\% de proteína bruta, 34,6\% de extrato etéreo e 16,3\% de matéria mineral (\% na matéria seca). No entanto, devido ao processamento a que são submetidos os produtos, ao tipo e à proporção dos constituintes, existe grande variabilidade no valor nutricional e energético desses ingredientes e essas discrepâncias podem proporcionar heterogeneidade nos resultados de desempenho zootécnico.

Apesar disso, existem poucos estudos avaliando a utilização desses resíduos na dieta de frangos de corte. Assim, realizou-se este trabalho com o objetivo de avaliar a viabilidade econômica do uso de farinha de resíduos da indústria de filetagem de tilápias em rações para frangos de corte e seus efeitos sobre o desempenho e os parâmetros sanguíneos.

\section{Material e Métodos}

O experimento foi conduzido no Aviário da Universidade Estadual do Oeste do Paraná, Campus de Marechal Cândido Rondon - PR.

Os dados de composição química, os valores de energia metabolizável aparente, aparente corrigida para o balanço de nitrogênio, os coeficientes de digestibilidade dos aminoácidos e os aminoácidos digestíveis verdadeiros da farinha de resíduos da indústria de filetagem de tilápia em estudo foram publicados por Eyng et al. (2009).

Para avaliar o efeito dos níveis de farinha de tilápia sobre o desempenho zootécnico das aves, foram utilizados 480 pintos de 1 dia, linhagem Cobb, com peso médio inicial de 43,87 g, distribuídos em delineamento inteiramente casualizado, com 5 dietas experimentais, 6 repetições e 16 aves por unidade experimental, em duas fases ( 1 a 21 dias e 22 a 42 dias de idade).

As dietas foram formuladas segundo recomendações nutricionais de Rostagno et al. (2005) e continham cada uma um dos cinco níveis de farinha de tilápia: 0, 2, 4, 6 ou 8\% (Tabela 1).

As características avaliadas foram ganho de peso, peso final, consumo médio de ração, conversão alimentar e mortalidade de 1 a 21 dias e 1 a 42 dias de idade. Os valores de mortalidade foram previamente transformados em raiz arcoseno. Aos 42 dias de idade, foi calculado o índice de eficiência produtiva.

Ao final do período experimental (42 dias de idade), as aves foram mantidas em jejum por 12 horas, para mensuração dos parâmetros sanguíneos. Duas aves por boxe foram separadas e delas foram retirados 5,0 mL de sangue por meio da veia braquial de uma das asas. O soro foi obtido por centrifugação do sangue e as leituras de triglicerídeos, cálcio e fósforo foram realizadas em espectrofotômetro com kits reagentes comerciais (KATAL).

Dentro da análise da viabilidade econômica foram calculados os custos das dietas experimentais, bem como o índice de eficiência econômica utilizado para calcular a quantidade de recursos despendidos em alimentação para produzir um quilograma de peso vivo e o índice de custo, segundo Bellaver et al. (1985).

Como procedimento estatístico, os dados de desempenho zootécnico foram submetidos à análise de variância e de regressão polinomial ou linear response plateau. Posteriormente, os dados obtidos com cada um dos níveis de farinha de tilápias foram comparados aos da ração testemunha, aplicando-se o teste de Dunnett. Para os resultados da análise econômica, a comparação de médias foi realizada pelo teste de Tukey. Todas as análises foram realizadas pelo programa SAS (2001).

\section{Resultados e Discussão}

A inclusão de farinha de tilápia no nível de $2 \%$ nas dietas melhorou o consumo médio de ração, o peso final e o ganho médio de peso no período de 1 a 21 dias de idade (Tabela 2). Para os demais níveis de inclusão, os parâmetros avaliados não diferiram $(\mathrm{P}<0,05)$ dos obtidos com a dieta controle.

Na análise de regressão para a fase de 1 a 21 dias, embora tenha variado de forma quadrática, o modelo linear response plateau foi o que apresentou a menor soma de quadrados dos desvios e que melhor se ajustou aos dados de peso final e ganho de peso, estimando a ocorrência de platô a partir do nível de 2,10 e 2,02\% de farinha de tilápia, respectivamente (Tabela 2). Para consumo de ração, o modelo linear response plateau foi o único que se ajustou aos dados, estimando a ocorrência de platô a partir do nível de $1,86 \%$ de inclusão.

Segundo Brumano et al. (2006), as aves mais jovens possuem menor capacidade de digestão e absorção dos nutrientes, visto que o sistema digestório encontra-se ainda em desenvolvimento, enquanto as mais velhas, com sistema digestivo plenamente desenvolvido, possuem maior tamanho do trato digestório e maior produção de enzimas e secreções gástricas e, consequentemente, melhor aproveitamento dos alimentos. Dessa forma, o fator idade pode ter influenciado a utilização dos nutrientes das dietas com maiores níveis de farinha de tilápia, fazendo com que os animais não obtivessem o máximo aproveitamento desse alimento. 
Tabela 1 - Composição das dietas experimentais utilizadas nas fases de 1 a 21 dias e de 22 a 42 dias de idade

\begin{tabular}{|c|c|c|c|c|c|c|c|c|c|c|}
\hline \multirow[t]{2}{*}{ Ingrediente } & \multicolumn{5}{|c|}{$\begin{array}{l}\text { Fase de } 1 \text { a } 21 \text { dias } \\
\text { Nível de farinha de tilápia (\%) }\end{array}$} & \multicolumn{5}{|c|}{$\begin{array}{l}\text { Fase de } 22 \text { a } 42 \text { dias } \\
\text { Nível de farinha de tilápia (\%) }\end{array}$} \\
\hline & 0 & 2 & 4 & 6 & 8 & 0 & 2 & 4 & 6 & 8 \\
\hline Farelo de soja & 37,04 & 34,69 & 32,34 & 29,99 & 27,64 & 29,09 & 26,74 & 24,39 & 22,04 & 19,69 \\
\hline Óleo de soja & 2,96 & 2,24 & 1,52 & 0,79 & 0,07 & 3,88 & 3,16 & 2,44 & 1,71 & 0,99 \\
\hline Fosfato bicálcico & 1,85 & 1,46 & 1,06 & 0,66 & 0,26 & 1,62 & 1,22 & 0,82 & 0,42 & 0,02 \\
\hline DL-metionina $99 \%$ & 0,32 & 0,31 & 0,31 & 0,31 & 0,31 & 0,24 & 0,24 & 0,24 & 0,24 & 0,24 \\
\hline L-lisina $\mathrm{HCl}$ & 0,30 & 0,31 & 0,32 & 0,33 & 0,34 & 0,27 & 0,28 & 0,29 & 0,30 & 0,31 \\
\hline L-treonina & 0,12 & 0,12 & 0,12 & 0,12 & 0,12 & 0,09 & 0,09 & 0,09 & 0,09 & 0,09 \\
\hline Antioxidante ${ }^{1}$ & 0,01 & 0,01 & 0,01 & 0,01 & 0,01 & 0,01 & 0,01 & 0,01 & 0,01 & 0,01 \\
\hline Anticoccidiano 2 & 0,05 & 0,05 & 0,05 & 0,05 & 0,05 & 0,05 & 0,05 & 0,05 & 0,05 & 0,05 \\
\hline Suplemento mineral ${ }^{3}$ & 0,05 & 0,05 & 0,05 & 0,05 & 0,05 & 0,05 & 0,05 & 0,05 & 0,05 & 0,05 \\
\hline \multicolumn{11}{|l|}{ Nutricional (calculada) } \\
\hline Energia metabolizável (kcal/kg) & 3.002 & 3.002 & 3.002 & 3.002 & 3.002 & 3.151 & 1.151 & 3.151 & 3.151 & 3.151 \\
\hline Proteína bruta (\%) & 21,99 & 21,99 & 21,99 & 21,99 & 21,99 & 18,99 & 18,99 & 18,99 & 18,99 & 18,99 \\
\hline Cálcio (\%) & 0,908 & 0,908 & 0,908 & 0,908 & 0,908 & 0,805 & 0,805 & 0,805 & 0,805 & 0,805 \\
\hline Fósforo disponível (\%) & 0,454 & 0,454 & 0,454 & 0,454 & 0,454 & 0,402 & 0,402 & 0,402 & 0,402 & 0,402 \\
\hline Lisina digestível (\%) & 1,276 & 1,276 & 1,276 & 1,276 & 1,276 & 1,073 & 1,073 & 1,073 & 1,073 & 1,073 \\
\hline Metionina digestível (\%) & 0,605 & 0,612 & 0,619 & 0,627 & 0,634 & 0,503 & 0,510 & 0,517 & 0,524 & 0,531 \\
\hline Metionina + cistina digestível (\%) & 0,907 & 0,907 & 0,906 & 0,906 & 0,907 & 0,772 & 0,772 & 0,772 & 0,772 & 0,772 \\
\hline Triptofano digestível (\%) & 0,240 & 0,236 & 0,232 & 0,227 & 0,223 & 0,201 & 0,197 & 0,192 & 0,188 & 0,184 \\
\hline Treonina digestível (\%) & 0,829 & 0,829 & 0,829 & 0,829 & 0,829 & 0,697 & 0,697 & 0,697 & 0,697 & 0,697 \\
\hline Potássio (\%) & 0,834 & 0,805 & 0,778 & 0,748 & 0,719 & 0,709 & 0,681 & 0,652 & 0,623 & 0,595 \\
\hline
\end{tabular}

${ }^{1}$ BHT (butil-hidroxi-tolueno); ${ }^{2}$ Salinomicina, 12\%; ${ }^{3}$ Suplemento mineral, conteúdo: magnésio - 16,0 g; ferro - 100,00 g; zinco - 100,0 g; cobre - 2,0 g; cobalto 2,0 g; iodo - 2,0 g; e veículo q. s. p. - 1.000 g; ${ }^{4}$ Suplemento vitamínico, conteúdo: vit. A - 10.000.000 UI; vit. D3 - 2.000.000 UI; vit. E - 30.000 UI; vit. B1 - 2,0 g; vit. B6 - 4,0 g; ácido pantotênico - 12,0 g; biotina - 0,10 g; vit. K3 - 3,0 g; ácido fólico - 1,0 g; ácido nicotínico - 50,0 g; vit. B12 - 15.000 mcg; selênio - 0,25 g; e veículo q. s. p. - $1.000 \mathrm{~g} ;{ }^{5}$ Avilamicina $10 \%$.

Tabela 2 - Desempenho zootécnico de frangos de corte submetidos a dietas contendo farinha de tilápia

\begin{tabular}{|c|c|c|c|c|c|c|}
\hline & \multicolumn{5}{|c|}{ Nível de farinha de tilápia (\%) } & \multirow[t]{2}{*}{ CV (\%) } \\
\hline & 0 & 2 & 4 & 6 & 8 & \\
\hline & \multicolumn{5}{|c|}{ Fase de 1 a 21 dias } & \\
\hline Consumo de ração $(g)^{1}$ & $1150,29 b$ & $1222,28 a$ & $1189,70 b$ & $1202,73 b$ & $1192,25 b$ & 3,18 \\
\hline Peso final $(g)^{2}$ & $847,83 b$ & $897,55 a$ & $885,21 b$ & $885,00 b$ & $887,60 \mathrm{~b}$ & 3,49 \\
\hline Ganho de peso $(g)^{3}$ & $804,26 b$ & $853,53 a$ & $841,39 b$ & $841,13 b$ & $843,53 b$ & 3,67 \\
\hline Conversão alimentar & 1,359 & 1,359 & 1,337 & 1,364 & 1,339 & $2,58 \mathrm{~ns}$ \\
\hline \multirow[t]{2}{*}{ Mortalidade (\%) } & $3,12 \mathrm{a}$ & $1,04 \mathrm{a}$ & ob & Ob & ob & 14,77 \\
\hline & \multicolumn{5}{|c|}{ Fase de 1 a 42 dias } & \\
\hline Consumo de ração $(g)^{4}$ & 4649,66 & 4795,95 & 4757,84 & 4777,64 & 4820,19 & 3,02 \\
\hline Peso final $(g)^{5}$ & 2703,40 & 2798,54 & 2768,14 & 2763,26 & 2778,57 & 2,62 \\
\hline Ganho de peso $(g)^{6}$ & 2659,83 & 2754,52 & 2724,32 & 2719,39 & 2734,50 & 2,66 \\
\hline Conversão alimentar ${ }^{7}$ & 1,72 & 1,71 & 1,72 & 1,73 & 1,73 & 1,24 \\
\hline Mortalidade (\%) & 4,17 & 4,17 & 5,21 & 2,08 & 2,08 & 24,05 \\
\hline Índice de eficiência produtiva ${ }^{8}$ & 351,27 & 362,12 & 351,45 & 364,59 & 364,51 & 5,89 \\
\hline
\end{tabular}

Média, na linha, seguida de letra distinta difere $(\mathrm{P}<0,05)$ da dieta controle pelo teste Dunnett.

ns = não-significativo a $5 \%$ de probabilidade pelo teste Dunnett.

${ }^{1} \mathrm{LRP}: \mathrm{Y}=1184,6236+2,0000 \mathrm{x}+6,6667 \mathrm{x}^{2}\left(\mathrm{R}^{2}=1,00\right)$

${ }^{2} \mathrm{LRP}: \mathrm{Y}=848,607+24,1721 \mathrm{x}-2,70938 \mathrm{x}^{2}\left(\mathrm{R}^{2}=0,98\right)$; Equação quadrática: $\mathrm{Y}=850,237+20,6396 \mathrm{x}-2,03006 \mathrm{x}^{2}\left(\mathrm{R}^{2}=0,94\right)$.

${ }^{3} \mathrm{LRP}: \mathrm{Y}=839,3641+3,0000 \mathrm{x}+14,0000 \mathrm{x}^{2}\left(\mathrm{R}^{2}=0,98\right)$; Equação quadrática: $\mathrm{Y}=806,572 * 103+20,5578 \mathrm{x}-2 * 02522 \mathrm{x}^{2}\left(\mathrm{R}^{2}=0,94\right)$.

${ }^{4}$ Equação linear: $\mathrm{Y}=4633,3+38,306 \mathrm{x}\left(\mathrm{R}^{2}=0,92\right)$.

${ }^{5} \mathrm{LRP}: \mathrm{Y}=2702,89+45,0529 \mathrm{x}-5,25757 \mathrm{x}^{2}\left(\mathrm{R}^{2}=1,00\right)$.

${ }^{6}$ Equação linear: $\mathrm{Y}=2680,3+20,974 \mathrm{x}\left(\mathrm{R}^{2}=0,93\right)$.

${ }^{7}$ Equação linear: $\mathrm{Y}=1,7004+0,0068 \mathrm{x}\left(\mathrm{R}^{2}=0,98\right)$.

${ }^{8}$ Equação linear: $\mathrm{Y}=344,21+5,5442 \mathrm{x}\left(\mathrm{R}^{2}=0,97\right)$. 
Outro fator que pode afetar o desempenho dos animais é a qualidade proteica dos ingredientes das rações. Segundo Anderson et al. (1993), a conservação da matéria-prima pode influenciar na qualidade da proteína. Longos tempos de estocagem podem causar degradação dos aminoácidos por atividades bacterianas, resultando em produção e acúmulo de aminas biogênicas que diminuem a qualidade proteica do produto final, uma vez que esses compostos tóxicos prejudicam o desempenho animal.

Ponce \& Gernat (2002) avaliaram o efeito da substituição da proteína bruta do farelo de soja por farinha de tilápia na dieta de frangos de corte e observaram melhoras no peso corporal, no consumo de ração e na conversão alimentar dos 14 aos 28 dias com níveis de substituição de 10 e 20\%, o que resultou em inclusão de 2,97 e 5,95\% de farinha de tilápia nas rações.

No período de 1 a 42 dias de idade, não foi observada diferença $(\mathrm{P}>0,05)$ nos parâmetros analisados (Tabela 2$)$, independentemente do nível de farinha de tilápia. Na análise de regressão para a fase de 1 a 42 dias (Tabela 2), a regressão linear ajustou-se aos dados para conversão alimentar, ganho de peso, consumo de ração e índice de eficiência produtiva. Para peso final, o modelo linear response plateau foi o único que se ajustou aos dados, estimando a ocorrência de platô a partir do nível de 2,26\% de farinha de tilápia.

Novello et al. (2007) não observaram efeito da inclusão de farinha de peixe (0, 4, 5 e 9\%) sobre o desempenho de frangos de corte. Da mesma forma, Ojewola et al. (2005) compararam a utilização de três fontes proteicas (farinhas de peixes inteiros e farinha de resíduo de processamento) e observaram que o desempenho das aves não foi influenciado pelas fontes proteicas. No entanto, analisando o efeito de elevados níveis de proteína oriunda de farinha de tilápia (0, 25, 50, 75 e 100\%) em substituição à proteína de farelo de soja em rações para frangos, Maigualema \& Gernat (2003) notaram diferenças nas características de peso da ave, consumo de ração e conversão alimentar no período de 7 até 42 dias de idade quando as aves receberam níveis acima de 50\% de proteína proveniente da farinha de tilápia.
Comparando os dados obtidos nas fases de 1 a 21 dias e de 1 a 42 dias, observou-se que a influência dos níveis de farinha de tilápia observada no período inicial não se manteve no período subsequente. Segundo Uni et al. (1998), a entrada alimentar exógena é acompanhada pelo desenvolvimento rápido do trato gastrintestinal e dos órgãos associados na assimilação desses nutrientes. Segundo esses autores, mudanças na secreção de algumas enzimas pancreáticas de 4 a 21 dias foram documentadas na literatura. Desta forma, a idade das aves parece ser responsável pela menor utilização na fase inicial.

Os valores de fósforo, cálcio e triglicerídeos apresentaram diferenças $(\mathrm{P}<0,05)$ entre os níveis de farinha de tilápia (Tabela 3 ). Nas aves alimentadas com as dietas com maiores níveis de farinha de tilápia (4, 6 e 8\%), os valores de cálcio e fósforo sanguíneos diferiram $(\mathrm{P}<0,05)$ dos obtidos com a dieta controle, sem farinha de tilápia, de modo que, quanto maior a inclusão da farinha, menor o nível sérico desses minerais.

Na análise de regressão para os parâmetros sanguíneos, o modelo linear response plateau foi o que se ajustou aos dados de fósforo e cálcio, estimando a ocorrência de platô a partir do nível de 6,07 e 5,51\% de inclusão, respectivamente. Observou-se aumento linear dos níveis de farinha de tilápia sobre os valores de triglicerídeos (Tabela 3).

Um fator que pode afetar a absorção dos minerais é a disponibilidade biológica, ou seja, a porção do nutriente que é efetivamente utilizada pelo animal. A grande variação da disponibilidade de cálcio nos alimentos deve-se principalmente à composição química da fonte suplementar utilizada, à combinação química e/ou da associação física do cálcio com outros componentes formando em alguns casos quelatos e fitatos de baixa solubilidade ou baixa disponibilidade (Nunes, 1995).

Neste trabalho os níveis de cálcio e fósforo disponível foram mantidos na mesma proporção para todos os níveis de inclusão e não houve influência da percentagem desses minerais fornecidos nas dietas.

As concentrações de triglicerídeos diferiram $(\mathrm{P}<0,05)$ entre os níveis de farinha de tilápia em comparação à dieta

Tabela 3 - Valores de parâmetros sanguíneos de frangos de corte aos 42 dias de idade alimentados com rações contendo farinha de tilápia

\begin{tabular}{|c|c|c|c|c|c|c|}
\hline & \multicolumn{5}{|c|}{ Nível de farinha de tilápia (\%) } & CV (\%) \\
\hline Fósforo $(\%)^{1}$ & $6,94 a$ & $6,60 a$ & $6,25 b$ & $5,99 b$ & $5,99 b$ & 9,08 \\
\hline Triglicerídeos $(\%)^{3}$ & $21,95 a$ & $26,02 \mathrm{a}$ & $25,46 a$ & $32,45 b$ & $34,37 b$ & 23,94 \\
\hline
\end{tabular}

Médias, na linha, seguidas de letra distinta diferem $(\mathrm{P}<0,05)$ pelo teste Dunnett da dieta controle.

${ }^{1} \mathrm{LRP}$ : Y = 6,94417 - 0,1772917x $\left(\mathrm{R}^{2}=1,00\right)$.

2 LRP: Y = 9,34509-0,16848x $\left(\mathrm{R}^{2}=0,99\right)$.

${ }^{3}$ Equação linear: $\mathrm{Y}=21,7972+1,56360 x\left(\mathrm{R}^{2}=0,88\right)$. 
controle. Os menores níveis de triglicerídeos no sangue foram obtidos com os menores níveis de farinha de tilápia. No entanto, Elswyk et al. (1994) afirmaram que aves que consomem uma dieta de pescados apresentam menor concentração de triglicerídeos e colesterol no plasma.

Segundo Suárez-Mahecha et al. (2002), esses efeitos são atribuídos à presença de ácidos graxos ômega-3, principalmente eicosapentaenoico (EPA) e docosahexaenoico (DHA). No entanto, espécies de água salgada apresentam maior concentração desses ácidos graxos, em decorrência do alto conteúdo de ácidos graxos poliinsaturados ômega-3 em algumas espécies de fitoplâncton marinho, contidas em sua dieta (Souza et al., 2007). Dessa forma, a não-redução dos níveis de triglicerídeos com a inclusão de farinha de tilápia pode ter sido causada pelo perfil de ácidos graxos da farinha.

Os resultados da análise econômica para utilização de farinha de tilápia na fase inicial de criação (1 a 21 dias), bem como no seu período total (1 a 42 dias) apresentaram diferenças $(\mathrm{P}<0,05)$ entre os níveis de inclusão para custo de ração, índice de eficiência econômica e índice de custo (Tabela 4).

No período de 1 a 21 dias, os índices de eficiência econômica e de custo foram melhores para a dieta controle ( $0 \%$ de inclusão), mas não diferiram $(\mathrm{P}>0,05)$ da dieta com 2\% de farinha de tilápia, portanto éigualmente viável a inclusão dessa proporção de farinha de tilápia na ração. O custo por kg de peso vivo produzido e o índice de custo aumentaram de acordo com os níveis de farinha de tilápia. Efeito negativo do aumento dos níveis de farinha de tilápia foi observado, no entanto, sobre o índice de eficiência econômica, comprovando que, com a inclusão de farinha de tilápia, houve maior custo ou menor eficiência econômica das rações.

No período de 1 a 42 dias, o menor custo de produção e os melhores índices de custo e eficiência econômica foram obtidos com a inclusão de farinha de tilápia no nível de 8\%. Neste caso, o custo por kg de peso vivo produzido e o índice de custo reduziram conforme o aumento dos níveis de farinha de tilápia, havendo uma melhoria no índice de eficiência econômica, efeitos contrários aos observados no período de 1 a 21 dias.

Tabela 4 - Custo da ração, índice de custo e índice de eficiência econômica da inclusão de farinha de tilápia na ração de frangos de corte

\begin{tabular}{|c|c|c|c|c|c|c|}
\hline & \multicolumn{5}{|c|}{ Nível de farinha de tilápia (\%) } & \multirow[t]{2}{*}{ CV (\%) } \\
\hline & 0 & 2 & 4 & 6 & 8 & \\
\hline \multicolumn{7}{|c|}{ Custo da ração por kg de peso ganho } \\
\hline 1 a 21 dias & $1,68 \mathrm{c}$ & $1,76 \mathrm{bc}$ & $1,80 \mathrm{~b}$ & $1,90 \mathrm{a}$ & $1,96 \mathrm{a}$ & 2,55 \\
\hline 1 a 42 dias & $1,34 \mathrm{a}$ & $1,28 b$ & $1,23 c$ & $1,19 \mathrm{~d}$ & $1,14 \mathrm{e}$ & 1,24 \\
\hline \multicolumn{7}{|c|}{ Índice de eficiência econômica (\%) } \\
\hline 1 a 21 dias & $99,84 a$ & $95,55 \mathrm{ab}$ & $93,10 b$ & $88,37 c$ & $85,70 \mathrm{c}$ & 2,88 \\
\hline 1 a 42 dias & $85,07 \mathrm{e}$ & $88,90 \mathrm{~d}$ & $92,37 \mathrm{c}$ & $95,91 b$ & $100,00 \mathrm{a}$ & 1,64 \\
\hline \multicolumn{7}{|c|}{ Índice de custo (\%) } \\
\hline 1 a 21 dias & $100,16 c$ & $104,73 \mathrm{bc}$ & $107,51 b$ & $113,28 a$ & $116,78 a$ & 2,99 \\
\hline 1 a 42 dias & $117,59 a$ & $112,53 b$ & $108,27 c$ & $104,29 d$ & $100,00 \mathrm{e}$ & 1,74 \\
\hline
\end{tabular}

Médias, na linha, seguidas de letras distintas diferem $(\mathrm{P}<0,05)$ pelo teste Tukey.

\section{Conclusões}

Em rações para frangos de corte na fase de 1 a 42 dias, a inclusão de farinha de tilápia em níveis de até 8\% não prejudica o desempenho das aves e ainda melhora o desempenho econômico e reduz as concentração sanguíneas de fósforo e cálcio.

\section{Referências}

ANDERSON, J.S.; LALL, S.P.; McNIVEN, M.A. Evaluation of protein quality of fish meal by chemical and biological assays. Aquaculture, v.115, p.305-325, 1993.

BELLAVER, C.; FIALHO, E.T.; PROTAS, J.F.S. et al. Radícula de malte na alimentação de suínos em crescimento e terminação.
Pesquisa Agropecuária Brasileira, v.20, n.8, p.969-974, 1985.

BRUM JR., B.S.; ZANELLA, I.; TOLEDO, G.S.P. et al. Dietas para frangos de corte contendo quirera de arroz. Ciência Rural, v.37, n.5, p.1423-1429, 2007.

BRUMANO, G.; GOMES, P.C.; ALBINO, L.F.T. et al. Composição química e valores de energia metabolizável de alimentos protéicos determinados com frangos de corte em diferentes idades. Revista Brasileira de Zootecnia, v.35, n.6, p.2297-2302, 2006.

EYNG, C.; NUNES, R.V.; POZZA, P.C. et al. Valor nutricional da farinha de resíduos da indústria de filetagem de tilápias. In: ZOOTEC, 2009, Águas de Lindóia. Anais... São Paulo: Zootec, 2009. (CD-ROM).

GERON, L.J.V.; ZEOULA, L.M.; VIDOTTI, R.M. et al. Digestibilidade e parâmetros ruminais de rações contendo silagens de resíduo da filetagem de tilápia. Acta Science Animal Science, v.28, n.4, p.437-445, 2006. 
MAiguALEMA, M.A.; GERNAT, A.G. The effect of feeding elevated levels of Tilapia (Oreochromis niloticus) by-product meal on broiler performance and carcass characteristics. International Journal of Poultry Science, v.2, n.3, p.195-199, 2003.

NOVELlo, D.; OST, P.R.; NEUMANN, M. et al. Avaliação zootécnica e qualidade da carcaça de frangos de corte alimentados com rações contendo farinha de peixe ou aveia branca. Ciência Rural, v.37, n.5, p.1430-1435, 2007.

NUNES, I.J. Nutrição animal básica. Belo Horizonte: 1995. $334 \mathrm{p}$.

OJEWOLA, G.S.; UDOM, S.F. Chemical evaluation of the nutrient composition of some unconventional animal protein sources. International Journal of Poultry Science, v.4, p.10, p.745-747, 2005.

PONCE, L.E.; GERNAT, A.G. The effect of using different levels of tilapia by-product meal in broiler diets. Poultry Science, v.81, p.1045-1049, 2002.
ROSTAGNO, H.S.; ALBINO, L.F.T.; DONZELE J.L. et al. Tabelas brasileiras para aves e suínos: composição de alimentos e exigências nutricionais. Viçosa, MG: UFV, Departamento de Zootecnia, 2005. p.186.

SOUZA, S.M.G.; ANIDO, R.J.V.; TOGNON, F.C. Ácidos graxos ômega3 e ômega-6 na nutrição de peixes - fontes e relações. Revista de Ciências Agroveterinárias, v.6, n.1, p.63-71, 2007.

SUÁREZ-MAHECHA, H.; FRANCISCO, A.; BEIRÃO, L.H. et al. Importância de ácidos graxos poliinsaturados presentes em peixes de cultivo e de ambiente natural para a nutrição humana. Boletim do Instituto de Pesca, v.28, n.1, p.101-110, 2002. STATISTICAL ANALYSIS SYSTEM - SAS. Painless Windows, a handbook for SAS users. 2.ed. Guelph: Jodie Gilmore, 2001. 61p.

UNI, Z.; GANOT, S.; SKLAN, D. Posthatch development of mucosal function in the broiler small intestine. Poultry Science, v.77, p.75-82, 1998.

Van ELSWYK, M.E.; HARGIS, B.M.; WILLIAMS, J.D. et al. Dietary menhaden oil contributes to hepatic lipidosis in laying hens. Poultry Science, v.73, p.653-662, 1994. 